\title{
Corrosion resistance of sulfated cements in carbonate and in carbonate-sulfate mediums
}

\author{
Svetlana Samchenko ${ }^{1}$, Olga Zemskova ${ }^{1}$, and Dmitriy Zorin ${ }^{1 *}$ \\ ${ }^{1}$ Moscow State University of Civil Engineering, Yaroslavskoe shosse, 26, Moscow, 129337, Russia
}

\begin{abstract}
Corrosion resistance of sulfated cements in carbonate and in carbonate-sulfate mediums has been studied. The samples have been placed in carbonate and carbonate-sulfate mediums for investigation stability of sulfated cements. The same researches were done with sulfate resistant portland cement to compare stability of samples. High corrosive resistant of sulfated cements is conditioned by forming dense and strong cement stone. The obtaining of corrosion resistant cements is possible with usage of the ordinary portland cement clinker with inclusion to them sulfoferrite and sulfoalumoferrite clinkers. Sulfated cements have the higher corrosion stability in contrast to ordinary sulfate resistant cement.
\end{abstract}

\section{Introduction}

It is a fact that cement stone has to withstand the most aggressive effects in buildings, because the concrete aggregate is inert respective the environment's aggressive factors. The $\mathrm{Ca}(\mathrm{OH})_{2}$ phase is the one most exposed to environmental impacts. Other hydration products are also prone to chemical factors, which cause their decomposition, compromise the strength of cement stone and make it less durable. Service life of concrete has been the point at issue for numerous R\&D congresses and conferences on the chemistry of cement [1-5]. At this time, lack of corrosion resistance in concretes is a priority problem [6-11]. Science has sought to raise resistance of concrete with various binding materials [12-15], additives and aggregates that enhance corrosion resistance [16-19].

Resistance of cement stone to the effects of aggressive solutions depends on porosity of samples. Research $[20,21]$ has demonstrated that carbonization of cement stone causes the pores to fill up with $\mathrm{CaCO}_{3}$ crystals, thus reducing its permeability and strength.

Impact from the carbonate environment on the cement stone is boosted by sulfate ions.

The issues of sulfate corrosion include the problem of late ettringite formation in hardened cement stone. Such delayed formation is possible due to interaction and recrystallization of calcium hydroaluminates with ions of $\mathrm{SO}_{4}{ }^{2-}$ adsorbed in $\mathrm{CSH}$ phases. In samples of sulfated cements, ettringite retains continuous stability within the structure of cement stone and therefore formation of secondary ettringite in the sample's inner layers does not occur. To identify stability of sulfated-cement stone, researchers examined samples hardened in carbonate and carbonate-sulfate mediums. Similar research examined sulfate-resistant Portland cement to compare their stability.

* Corresponding author: dim-z@yandex.ru 


\section{Experimental}

For the purposes of research, we prepared mixes of sulfate-resistant Portland cement and Portland cement with added clinker of sulfoferrite and sulfoalumoferrite. To manufacture sulfate-resistant Portland cement, we used russian standard GOST-compliant regulatedcomposition clinker, while for sulfated cements we used standard Portland cement clinker. For clinker mix components, see Table 1.

Table 1. Mineralogical composition of clinkers (\%)

\begin{tabular}{|c|c|c|c|c|}
\hline Cements & $\mathrm{C}_{3} \mathrm{~S}$ & $\mathrm{C}_{2} \mathrm{~S}$ & $\mathrm{C}_{3} \mathrm{~A}$ & $\mathrm{C}_{4} \mathrm{AF}$ \\
\hline Sulfate resistant & 50 & 28 & 3,6 & 14 \\
\hline Portland cement & 60 & 11 & 8 & 21 \\
\hline
\end{tabular}

Cements were treated in a ball drum with inter-grinding to specific surface of 320 $\mathrm{m}^{2} / \mathrm{kg}$. For composition of cement mix, see Table 2 .

Table 2. Composition of cements (\%)

\begin{tabular}{|c|c|c|c|c|c|}
\hline & Cement & $\begin{array}{c}\text { PC- } \\
\text { clinker }\end{array}$ & $\begin{array}{c}\text { SFC } \\
\text { (sulfoferrite) }\end{array}$ & $\begin{array}{c}\text { SAFC } \\
\text { (sulfoalumoferrite) }\end{array}$ & Gypsum \\
\hline 1 & $\begin{array}{c}\text { SRC } \\
\text { (sulfur-resistant } \\
\text { cement) }\end{array}$ & 100 & - & - & 5 \\
\hline 2 & PC+SFC & 93 & 7 & - & 5 \\
\hline 3 & PC+SAFC & 93 & - & 7 & 5 \\
\hline
\end{tabular}

Corrosion resistance of samples was evaluated by changing physical and mechanical properties of samples made of cement paste 1:0 with normal thickness, stored in aggressive mediums, specifically water and $5 \%$ water solution of $\mathrm{Na}_{2} \mathrm{SO}_{4}$ through which carbonic acid was passed. Characteristics of aggressive solutions are given in Table 3.

Table 3. The performance aggressive solution

\begin{tabular}{|c|c|c|c|}
\hline Type of solution & Hardness, $\mathrm{mmol} / \mathrm{l}$ & $\mathrm{CO}_{2}, \mathrm{mg} / \mathrm{l}$ & $\begin{array}{c}\text { Stability of } \\
\text { medium }\end{array}$ \\
\hline Carbonate & 32.5 & 17 & $<1$ \\
\hline Carbonate-Sulfate & 76.5 & 35 & $>1$ \\
\hline
\end{tabular}

The above solutions are aggressive to concrete and iron, because concentration of free carbonic acid is above the equilibrium.

The resistance ratio was found as the sample's bending strength while hardening in the corrosive environment and potable water.

To measure porosity of samples, we used the volume-weight bottle method and the mercury-based method.

The processes of hydration and carbonization were studied with X-ray phase analysis and electron microscope examination of the chipped surface of samples.

\section{Evaluation}

Adding sulfoferrite or sulfoalumoferrite clinkers to the cement mix contributes to formation of a dense strong structure of cement stone with lower content of $\mathrm{Ca}(\mathrm{OH})_{2}$. This happens because hydration of calcium sulfoferrite and calcium sulfoalumoferrite goes along with $\mathrm{Ca}(\mathrm{OH})_{2}$ binding to produce ferrous ettringite. Creation of a dense strong structure ensures 
higher corrosion resistance of sulfated cements. Measured key construction and engineering properties of cements are illustrated in Table 4.

Table 4. Properties of cements

\begin{tabular}{|c|c|c|c|c|}
\hline \multirow{2}{*}{ №№ } & \multicolumn{2}{|c|}{ Strength } & \multirow{2}{*}{$\begin{array}{c}\text { Expansion, \%, after } 6 \\
\text { month }\end{array}$} & \multirow{2}{*}{$\begin{array}{c}\text { Crack resistant, } \\
\text { days }\end{array}$} \\
\hline & Compressive & Bending & & \\
\hline 1 & 143 & 35 & - & 31 \\
\hline 2 & 155 & 62 & 0.07 & 53 \\
\hline 3 & 162 & 68 & 0.08 & 55 \\
\hline
\end{tabular}

The information of the above Table makes it obvious that sulfated cements excel sulfate-resistant Portland cements in strength and crack-resistance, and therefore they are more resistant in aggressive mediums as evidenced by their high resistance coefficients (see Fig. 1 and 2).

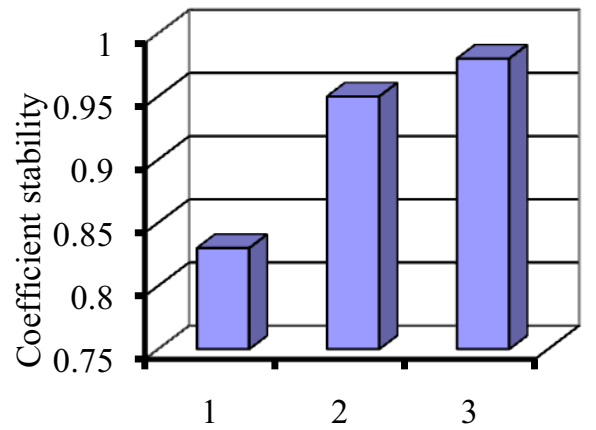

Fig.1. Resistance of cements in carbonate medium. Sample number according to Table 2.

Higher corrosion resistance of samples exists thanks to formation of dense stone with lower porosity (Fig. 3 and 4). As suggested by the presented data, porosity of sulfateresistant Portland cement in carbonate environment first rises but later falls, only to rise again. This phenomenon exists because $\mathrm{Ca}(\mathrm{OH})_{2}$ gets leached in open pores at the initial stage, but later $\mathrm{CaCO}_{3}$ crystallizes and accumulates, reducing the stone's porosity. As $\mathrm{CaCO}_{3}$ subsequently gets dissolved and washed out of the cement stone structure, this causes growth of porosity.

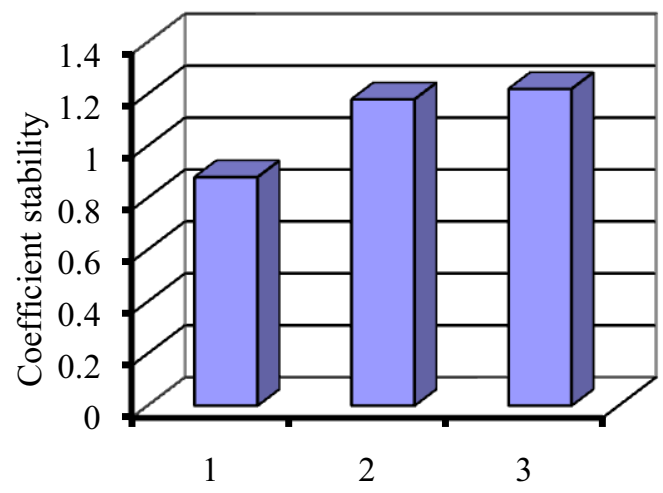

Fig. 2. Resistance of cements in carbonate -sulfate medium. Sample number according to Table 2. 


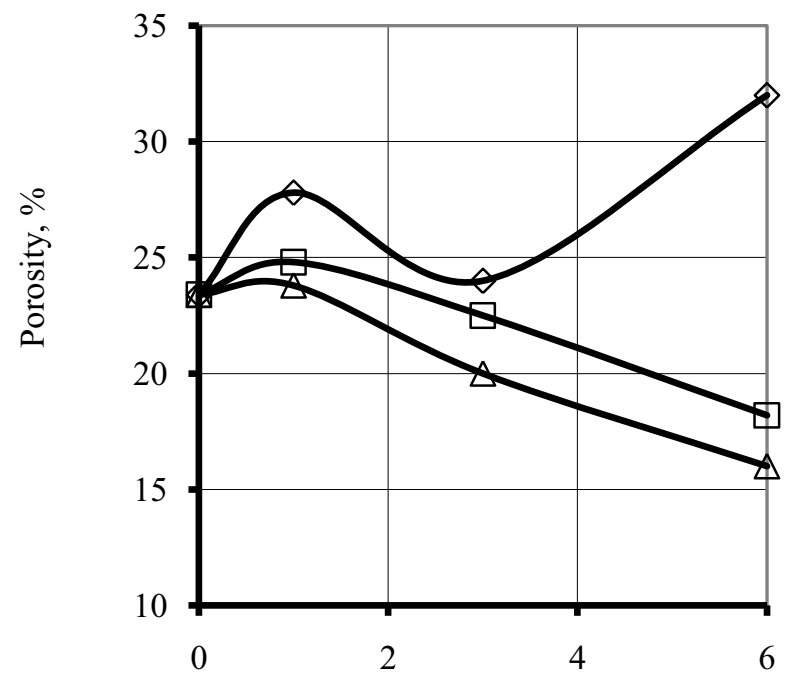

Time o hardening, month

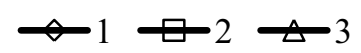

Fig.3. Overall porosity of cement stone in carbonate medium. Sample number according to Table 2

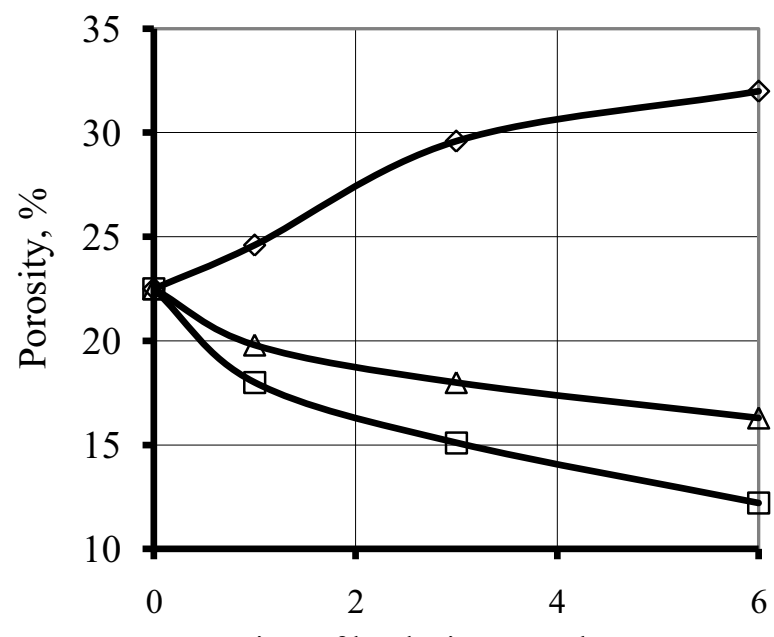

Time of hardening, month

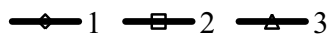

Fig. 4. Overall porosity of cement stone in carbonate-sulfate medium. Sample number according to Table 2

Presence of sulfates in a carbonate environment intensifies the aggressive effects of carbon dioxide on the cement stone made of sulfate-resistant Portland cement, as it enables 
crystallization in the pores for both $\mathrm{CaCO}_{3}$ and $\mathrm{CaSO}_{4} \cdot 2 \mathrm{H}_{2} \mathrm{O}$. This creates stretching forces in the sidewalls of pores and capillaries, at the same time increasing general porosity.

Samples of sulfated cements in all mediums featured lower general porosity. In cement stone, pores get clogged up with both hydro-carboaluminate and hydro-sulfoferrous compounds, and packed with gel-like products of hydration.

Compared to sulfated cements, sulfate-resistant Portland cements tend to absorb more carbonate ions from aggressive solutions, as we can clearly see from Table 5.

Table 5.The contents of carbonates - ions (\%) in recalculation on $\mathrm{CO}_{2}$ in samples, hardened in aggressive solutions

\begin{tabular}{|c|c|c|c|c|c|c|}
\hline & \multicolumn{3}{|c|}{$\begin{array}{c}\text { Carbonate medium, } \\
\text { after month }\end{array}$} & \multicolumn{3}{c|}{ Carbonate-sulfate medium, month } \\
\cline { 2 - 7 } & 1 & 3 & 6 & 1 & 3 & 6 \\
\hline 1 & 2.33 & 2.55 & 3.09 & 2.15 & 2.30 & 2.89 \\
\hline 2 & 1.12 & 1.43 & 1.50 & 1.02 & 1.38 & 1.44 \\
\hline 3 & 1.09 & 1.25 & 1.45 & 0.96 & 1.18 & 1.40 \\
\hline
\end{tabular}

According to the XRD and electron microscopy, the internal structure of the samples remains unchanged as they harden in an aggressive environment. The upper layer of samples hardened in the carbonate environment contained $\mathrm{CaCO}_{3}$ in the case of sulfateresistant Portland cement, and hydrocarboaluminates or hydrocarboferrites in the samples of sulfated cements. Samples hardened in the carbonate-sulfate environment, in the upper layer contained $\mathrm{CaCO}_{3}$ and $\mathrm{CaSO}_{4} \cdot 2 \mathrm{H}_{2} \mathrm{O}$ in sulfate-resistant Portland cement, while hydrocarbonate compounds and calcium trihydrosulfoaluminate was found in sulfated cements. During the first stage of hardening, those were tiny individual crystals, but large clusters of druses were observed 6 months later, and the top layer was highly compacted and going 0.7-1 mm deep.

During long storage in carbonate and carbonate-sulfate solutions, the process of protection layer forming triggered by carbonate and sulfate ions is more intensive compared to leaching and decomposition of the surface hydrate phases in cement stone. Generation of top layers prevents penetration of aggressive solutions into the cement stone.

\section{Conclusion}

High corrosion resistance of sulfated cements is created by formation of compact and strong cement stone. Corrosion-resistant cements can be made with standard Portland cement clinkers, with sulfoferrite or sulfoalumoferrite clinkers added. Sulfated cements possess higher corrosion resistance comparable to that of sulfate-resistant Portland cement with standard regulated mix.

\section{References}

1. T.V. Kouznetsova, Y.R. Krivoborodov, S.V. Samchenko, I.Y. Burlov In: Proceed. 13th ICCC, 198.1 (2011)

2. J. Stark, K. Bolman In: 2 Intern. Conference on Chemistry and Technology of Cement.-Moscow. 1,64 (2000)

3. S.V. Samchenko In: 15 Int. Baustofftagung. Weimar. Bundesrepublik Deutchland. 2. 2-1109 (2003)

4. T.V. Kouznetsova, S.I. Ivaschenko, S.V. Samchenko In: Proceed. 11th ICCC, 2076 (2003) 
5. T.V. Kouznetsova, S.V. Samchenko, E.N. Anpilogova In: 16 International Baustofftagung. Weimar. Deutchland. 1. 1-0221 (2006)

6. N.K. Rozental In: Beton i zhelezobeton 6, 29-31 (2007)

7. A.M. Popesko, O.I. Ancygin, A.A. Dajlov In: Beton i zhelezobeton 2, 11-13 (2006)

8. V.F. Stepanova In: Promyshlennoe i grazhdanskoe stroitelstvo [Industrial and civil engineering] 1, 13-16 (2013)

9. V.F. Stepanova In: Construction materials, the equipment, technologies of XXI century 3, 16 (2005)

10. L.Ja. Kramar, B.Ja. Trofimov, E.A. Gamalij In: Journal Cement and its Applications 4, 127-131 (2011)

11. V.V. Rusina, E.V. Korda, S.A. L'vova In: Stroitel'nye Materialy 8, 29-31 (2011)

12. L.V. Judina, V.V. Turchin, S.V. Sychugov In: Suhie stroitel'nye smesi 5, 22-28 (2015)

13. V.I. Kalashnikov, K.N. Mahambetova In: Stroitel'nye Materialy 11, 12-13 (2010)

14. A.S. Brykov, A.S. Vasil'ev, M.V. Mokeev In: Journal Cement and its Applications 5, 59-63 (2013)

15. G.S. Rojak, I.V. Granovskaja In: Journal Cement and its Applications 3, 104-106 (2011)

16. A.V. Buchkin, V.F. Stepanova In: Stroitel'nye Materialy 7, 82-83 (2006)

17. K.B. Safarov, V.F. Stepanova In: Stroitel'nye Materialy 5, 70-73 (2016)

18. V.F. Stepanova, A.V. Buchkin In: Construction materials, the equipment, technologies of XXI century 9, 22-26 (2011)

19. G.M. Kondrashev In: Beton i zhelezobeton 5, 22-25 (2006)

20. Y.R. Krivoborodov, S.V. Samchenko In: Proceed. 12th ICCC, 1.006 (2007)

21. T.V. Kouznetsova, S.V. Samchenko, I.Y. Burlov, Cementitious Materials as Model Nanostruture and Transport Processes (Centro Stefano Franscini Monte Verita, Switzerland, 177 (2005) 